\title{
Social Technologies as an Instrument for the Modernization of Social Space in the Social and Labor Sphere
}

\author{
Lyutsiya Mugtabarovna Gaisina ${ }^{1}$, Ramil Nasifovich Bakhtizin ${ }^{1}$, \\ Irina Mikhaylovna Mikhaylovskaya ${ }^{1}$, Nursafa Gafurovna Khairullina ${ }^{2}$ \\ and Marina Lvovna Belonozhko ${ }^{2}$
}

\begin{abstract}
${ }^{1}$ Ufa State Petroleum Technological University, Russia, Republic of Bashkortostan, 450062, Ufa, Kosmonavtov Str., 1

${ }^{2}$ Tyumen State Oil and Gas University, Volodarskiy Str., 38, Tyumen, 625000, Russia.
\end{abstract}

DOI: http://dx.doi.org/10.13005/bbra/1979

(Received: 10 September 2015; accepted: 17 October 2015)

\begin{abstract}
Social changes have a feature, namely, they cover all the social space of any society. Social changes are manifested both in the transformation of the institute and in the reflexive change of social practices at the level of the enterprise. Accordingly, the change of the management paradigm and the social relations take place in the social and in labour sphere. In this article the necessity of introducing the social technologies into the practice of management services staff is considered. The author has proposed a classification of social technologies, the staff development technology and the algorithm of implementation of social technologies in the sphere of personnel management. The analysis of the results of the author's research on the problems of social changes affecting the personnel management system and the nature of social dynamics in a team has been given in this article. According to the results of the conducted survey in the observable organizations violation of the principle of social justice and existence of a problem of motivation of the personnel, caused by insufficiently high level of a salary is revealed.
\end{abstract}

Key words: Social changes, personnel management, social technologies, algorithm of implementation, social communication, construction, transformation, staff development.

The transition from a centralized-planned to market systems of managing dictates the necessity of further evolution of approaches to personnel management. Transformation of the Russian society has led to the emergence of new management paradigms adequate time requirements. The main strategic resource is the human capital which in turn actualizes the need for thorough and complete study of the problem of personnel management as a complex social phenomenon.

\footnotetext{
* To whom all correspondence should be addressed.
}

Modern Russian society is undergoing dynamic transformation of social systems and socio-cultural practices that enhances the role of the communicative component in social processes. The above forms the need for introduction of new technologies into the practice of activity of personnel management services. There is a need of specific technologies in social planning, designing, and prediction of the staff development in the conditions of adaptation of the management system of the organization to the conditions of social changes. Social changes affect both the institute of management and the reflexive change of social practices, which has led to the changes of the personnel management system. The man is governed not by the people, but by needs and interests, that causes the need for submission of the last ones to the goals of the organization. 
According to the authors, at present social and labour relations continue to survive the crisis. The study of social changes is developing in two directions. It is possible to distinguish two approaches in studying of the crisis nature of these processes. One of the approaches highlights the global nature of the changes occurring under the influence post-industrial technologies and social changes adequate to them. Globalization is also considered as an important factor. Such an approach is quite clearly shown in the work of T. I. Zaslavskaya (Zaslavskaya, 2004) where it is noted that transformational activity leads to creation of the new institutionalized laws of the game of formal and informal nature. And though transformation behavior doesn't create aloof social result, however indirectly it attracts institutionalization, adjustment or ignoring of reforming rules. The authors suppose that transformational behavior is developed in the conditions of crisis and transforms social and labour relations. This can be seen in the loss of the senseforming function of labour, and namely, in its transformation from a way of life to means of survival.

Thus, this crisis factor should be marked as "the devaluation of labour values". It is represented that this trend is typical not only for the Russian management practice (Gayfullin and Rybalko, 2011; Mikhaylovskaya and Sultanova, 2014; Khairullina, 2012; Silin and Khairullina, 2004). The reasons of this process are much deeper, they have a basis in evolution of the world economic system.

Another approach is based on ascertaining of specific features of Russian reality, its conditionality of social, cultural and geoeconomic factors. In this context, the crisis phenomena in the field of personnel management are considered through the prism of the "heritage" of planned and economical system which is shown in preservation of former valuable purposes of system. Within this approach the factor aggravating the situation is the fact that the collectives of the enterprises are presented by individuals dividing the values of different types of society. In management activity there is a contribution of the manager taken separately and joint activity. Based on the foregoing, it is evident that the existence of different value systems of representatives of different level of management will inevitably lead to complication of management of the labour relations and respectively the reduction of contradictions between the head and performers can lead to the improvement of administrative processes.

Based on the foregoing, the authors allocate the following specific crisis factors inherent only in Russia: lack of a clear understanding of values, lack of continuous educational process throughout the work. In addition, there is an imbalance of labour statuses which is shown in branch, professional, official and territorial aspects. Confirmation of that the result of the work does not allow to provide a worthy standard of life of workers is traced through the Gini coefficient, which reflects the share of the total income falling on 10 percent of the richest population (Figure 1).

The present data reflect the beginning of the formation in the Russian Federation marginal economy and consequently reducing the value of labour and changing the attitude by the employee.

The crisis situation in 2008 led to the contradiction inertia and qualitative changes in the social sphere. It is impossible not to agree with the thesis of L.V. Korel, according to which many means of adaptation in crisis bifurcation environments are institutionalized first of all and normative regulatory ones are destroyed and personal and status characteristics of subjects are at the forefront (Korel, 1997). The Emergence of the need for development and introduction of social technologies as the instrument of social space of modernization in social and labor sphere has become the result of this contradiction.

The basis of studying of social technologies has been formed by the school of sociology and the theory of management of Bulgarian scientists (M. Markov, N. Stefanov). The following remark was stated in conformity with technologies by Bulgarian philosopher $\mathrm{N}$. Stefanov: "where people refer to the processes surrounding them actively and purposefully, when they change natural and social environment consciously and systematically, the technology is possible there, in principle” (Stefanov, 1976). Thus, if the "technology" reflects the need for a certain skill, "social" - its orientation. In total these components represent a way and nature of social space. 
J.T. Toshchenko identifies the following essential characteristics of social technologies: social technology represents a certain way of achievement of the social purposes; the essence of this method consists of pooperational implementation of activity; operations are developed in advance, consciously and systematically; this development is carried out on the basis and with the use of scientific knowledge; when developing the specificity of sphere is considered in which activity is carried; social technology is seen in two forms: as a project containing the procedures and operations and as the activity itself constructed according to this project (Toshchenko, 2001).

Thus, social technologies can be interpreted in the broad sense, understanding their view of social theory, studying specific operations with the results of cognitive activity, and in the narrow sense - as an instrument for modernization of social space aimed at optimization or exclusion of those operations that are not necessary for receiving social result. Social technologies of personnel management should include quantitative and qualitative transformation of the forms and methods of work with staff (Gaisina, 2010).

\section{METHOD}

\section{Author's classification of social technologies}

The diversity of social technologies caused the need for their systematization and allocation of more acceptable ones for the management staff. The classification of social technologies which was carried out by the authors is reflected in Figure 2.

The systematization of social technologies presented in the literature in the sphere of personnel management system and their correlation with earlier given author's vision of a personnel management system allows to subdivide them into the following: hiring of the personnel, its adaptation; staff development; stimulation and motivation of the personnel; formation of feeling of job satisfaction, formation of a solid team (Gaisina, 2015).

Conceptual design of social technologies in the field of personnel management receive within the bounds of the following theories:

a) theories of action (M. Weber, G. Zimmel); b) kongnitivizm (T.A. Van Dyck, V.A. Vorkachev);

c) social communication (A.V. Dmitriev, T.M. Dridze, E.V. Sykes);

d) conflictology (A.V. Dmitriyev, A.V. Vishnevskaya).

Social technologies involve purposeful action on the social object, in order to receive a given result, which in turn demands formation of a certain algorithm of influence with the given stage of procedures. Thus social technologies have to be directed both on transformation of a personnel management system, and on qualitative transformation of the organization.

Thus, the implementation of social technologies is possible under the condition of social construction through the formation of a certain algorithm (Gaisina, 2015; Belonozhko and Lavrishchev, 2013; Khairullina, 2012; Silin and Khairullina, 2004).

\section{Author's algorithm of realization of social technologies in the sphere of personnel management}

Under the algorithm is a set of purposeful actions, characterized by the strict sequence ðand mutual consistency. Initially, the term originates in mathematics and is regarded as certain actions on mathematical objects. Recently there has been algorithmization almost of any activity that leads to a transition from a clear mathematical understanding to a logical interpretation of the sequence of actions, often having formalization (Bakhtizin et al., 2001). In this case systematization of activity will be expressed in search, research and improvement of algorithm.

Author's vision of algorithm of realization of social technologies in the sphere of human resource management is presented in Figure 3.

Block A reflects the preparation and formation of social technology. Its realization takes place when the existing methods and the principles don't provide effective functioning of a personnel management system and aren't a key to ensuring competitiveness of the organization. At a stage diagnostics of a personnel management system on the basis of such methods of collecting primary information as supervision, questioning, interview, testing, group discussion and so forth is carried out. 
Thus the essence of the block is made not by the implication of production technologies in reality of public life, but design of the technologies adequate to a new administrative paradigm. In this regard V.N. Ivanov and V.I. Patrushev's opinion is actual who consider that realization of knowledge - is "a generic term of technologization, process of materialization, objectivization of any knowledge" (Ivanov and Patrushev, 2001). Based on this, this unit is the connection between scientific views and the sphere of their implementation.

Block B is based on the acceptance of the thesis that the social functions of human resource management system are converted under the influence of the revision of the management paradigm and are not based on "costly" indicators, but social needs of staff. This block includes hiring of the personnel and adaptation, development of the personnel, stimulation and motivation of the personnel, formation of feeling of satisfaction with work and a solid team. It is possible to allocate a large group of scientific publications, determining the content of specific social technologies. They mention vocational training, hiring, motivation of the personnel, considering social aspects of application of technologies in the activity of the companies (M.I. Magura, M.B. Kurbatov, P. Sheyl, V.V. Shcherbina, L.L. Bayars, to L.V. Ru, etc.) (Magura, 2004).

The essential attention must be paid to the design of personal subsystem of organization. In this regard, in terms of content, given in section $\mathrm{B}$, technologies of development of the personnel play a special role, that is caused by the process of changing of paradigms in management. According to the authors, technologies of development should be focused on formation and development of the competences representing mutually crossing of production tasks with abilities of the person. Actually competences are a product of interaction of challenge and creative abilities of the individual and can't be created only by training. It imposes new requirements to social technologies of development of the personnel.

Block B assumes an assessment of conformity of results to target reference points and the correcting procedures. At an evaluation stage of results the validity of social technology is defined. As realization of social technology assumes various level influence, so at the level of certain employees it should be traced the change of such indicators as satisfaction with the contents and process of labour, emergence of a sense of self-realization, self-identification of the worker with the enterprise. At the group level there has to be a formation of favorable social and psychological climate and command spirit, activization inside and intergroup interactions, reduction of the conflicts, complementarity of structures of the management and leadership. At the organization level, organizational culture is being formed, adequate to the characteristics of management and the objectives of professional development of employees.

Management as an activity involves the implementation of a number of functions, one of which is control (Bondarenko, 2014; Gaifullin and Sadykov, 2012; Belonozhko and Skifskaya, 2011). The structure of social institutions is multifaceted: it implies the existence of roles and statuses, formal and informal rules, principles and norms governing the status-role interaction factors of management relations. Along with this sanctions should take place and control the simple implementation of prescribed roles, statuses and observance "of rules of the game", as well as mechanisms for implementation of sanctions. One of the main tasks of management is the adjustment of the control system from the type "as is" and "as should be", which causes the use of correction procedures, also presented in the final block.

\section{Specification of social technology of staff development}

Due to the fact that, in the light of paradigmatic changes social technology of staff development is one of the most important and it seems appropriate to focus on its details (Gaisina, 2015). Graphical reflection of this technology is shown in Figure 4.

The scheme presented by the authors is rather algorithmic and is considered as the guide to action in the implementation of transformation of the personnel management system. It is also necessary to note that it should be recognized optional if personal features of the personnel will be considered. It is impossible to exclude from consideration the peculiarities of Russian mentality, morals, morality, and religion (Bondarenko, 2014). The presented set of methods isn't exhaustive and 
can be added taking into account specifics of concrete object of management.

\section{RESULTS}

\section{The ratio of staff to changes in society}

Let's consider the nature of the changes taking place in the oil and gas companies. Subjective assessment of the respondents about their perception of changes allow us to trace the main trends taking place in society and the nature of their influences on the system of personnel management. In each case the changes are perceived positively or negatively, so the research task was to provide the views of the group about the quality of the changes taking place in the team, in the organization, in society.

Respondents were asked the question "How do you perceive the changes in your organization?”, concerning the perception of the atmosphere in the team, the level of remuneration, the relationship between the chiefs of the staff

Table 1. Detailing abbreviations

\begin{tabular}{|c|c|c|c|}
\hline Symbol & Element & Work stage (character of an element) & Work methods \\
\hline I & Input & $\begin{array}{l}\text { Target system - transformation of the system of personnel } \\
\text { management }\end{array}$ & - \\
\hline W & Subset & Selection of target criteria & M1 \\
\hline$\Sigma$ & Linked object & $\begin{array}{l}\text { Mechanism of transformation of a personnel } \\
\text { management system }\end{array}$ & - \\
\hline II & Procedure & Selecting a method & M1, M2 \\
\hline III & Procedure & The choice of instruments & M1, M2 \\
\hline $\mathrm{f} 1, \mathrm{f} 2, \mathrm{f} 3$ & Subset & Selection of the most relevant instrument & M1 \\
\hline $\mathrm{P}$ & Linked object & $\begin{array}{l}\text { Groups of indicators of transformation of a } \\
\text { personnel management system }\end{array}$ & - \\
\hline G1, G2 & Linked object & $\begin{array}{l}\text { System of plans and programs of } \\
\text { development of a personnel management } \\
\text { system }\end{array}$ & - \\
\hline IV & Procedure & Definition of group & M1, M3 \\
\hline $\mathrm{V}$ & Procedure & $\begin{array}{l}\text { Application of the chosen method and the } \\
\text { instrument (instruments) to group }\end{array}$ & f, M \\
\hline VI & Procedure & $\begin{array}{l}\text { Measurement of results of realization of the } \\
\text { "development of the personnel” technology }\end{array}$ & M4 (w) \\
\hline VII & Procedure & $\begin{array}{l}\text { Assessment of efficiency of actions for } \\
\text { development of the personnel }\end{array}$ & $\mathrm{M}(4)$ \\
\hline VIII & Output & $\begin{array}{l}\text { New quality of a personnel management } \\
\text { system of the organization as a result of } \\
\text { introduction of technology }\end{array}$ & - \\
\hline Ì1 & Method & Expert method & - \\
\hline Ì2 & Method & Analogy method (analysis of experience) & - \\
\hline İ3 & Method & Selection, group & - \\
\hline Ì4 & Method & Measurement, comparison & - \\
\hline
\end{tabular}

and subordinates, the nature and intensity of the working process, etc.

Analysis of respondents' answers showed that, on average, in the opinion of the greater part of the respondents, the changes are positive. Thus every fourth doesn't see any changes which impacted on a personnel management system or nature of social dynamics in collective.
At the same time $28 \%$ highlight positive changes that are mainly manifested in the level of remuneration, in the subjective attitude towards their work and satisfaction with its results, as well as in the attitude of the authorities to the staff.

Thus $47 \%$ of respondents called the happened changes negative. In this connection it is appropriate to compare the results with the conclusions of the G.A. Shcherbakov, who 


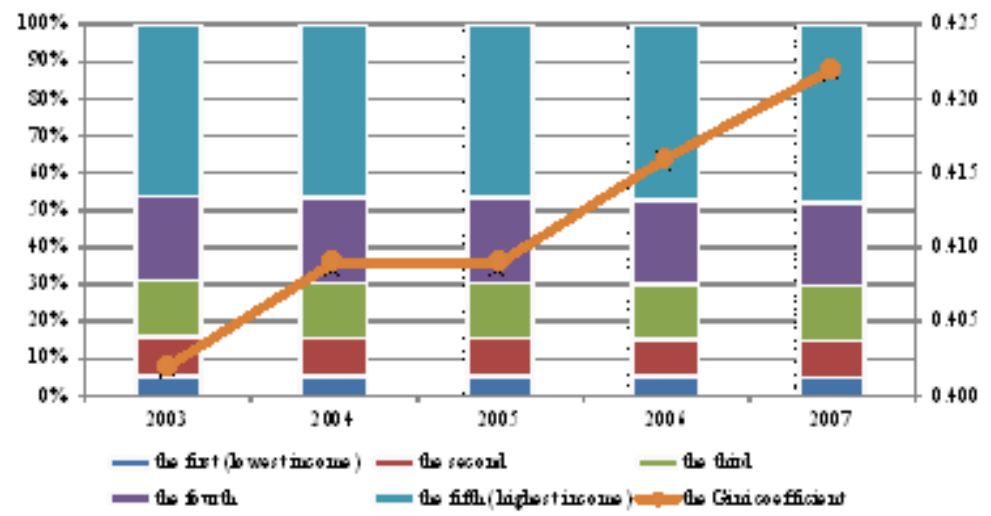

Fig. 1. The dynamics of the distribution of total income on $20 \%$ groups of the population, $\%$ (Indicators of living standards of the Russian Federation. Income and expenses, 2015)

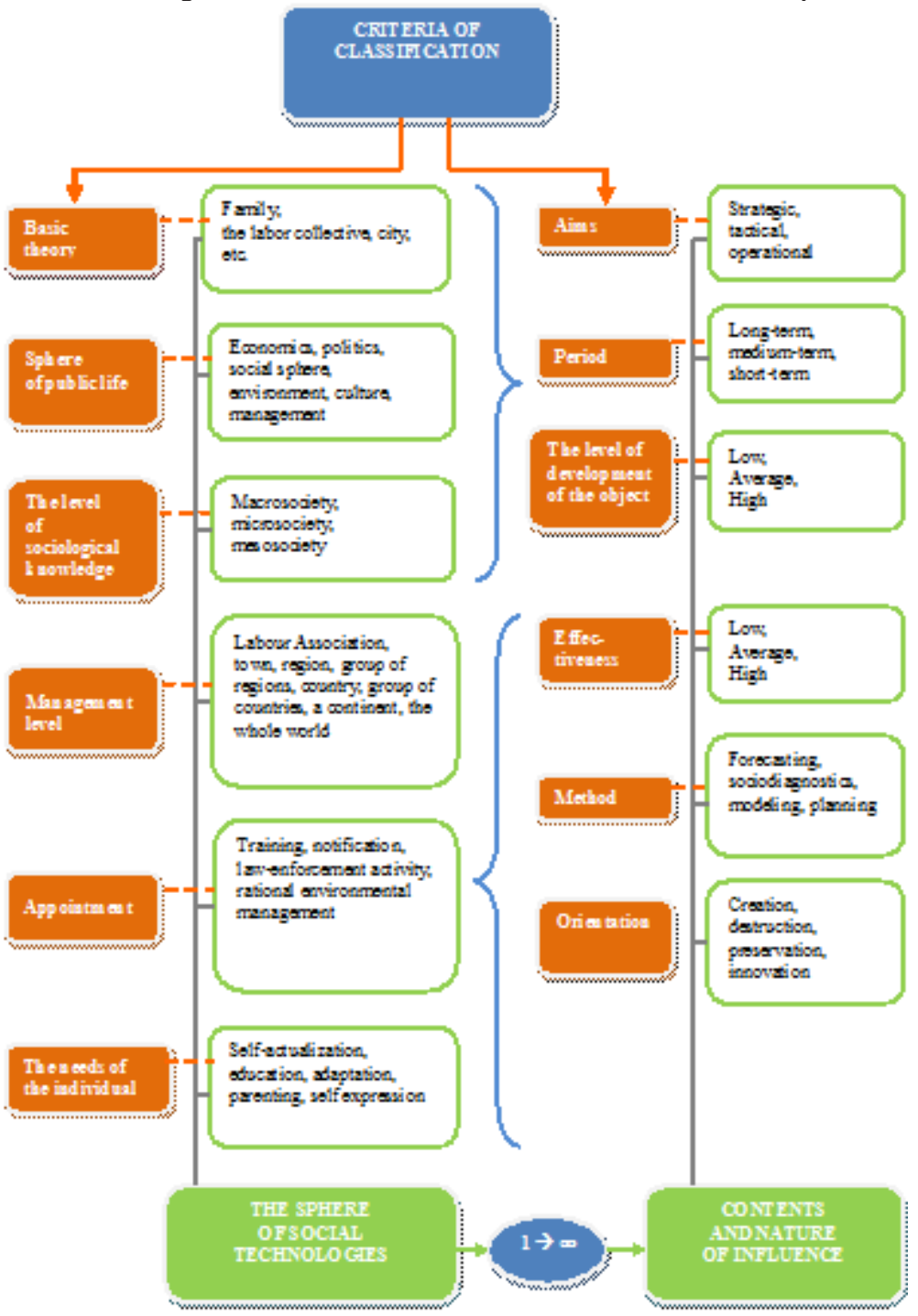

Fig. 2. Author's classification of social technologies 


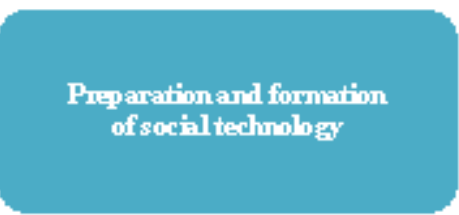

- BLOCKA

- Idertification of targets in the pesormel mamagement system

- Identification of poblems in personnel management

- Structuring problems

- Development of social techmologies

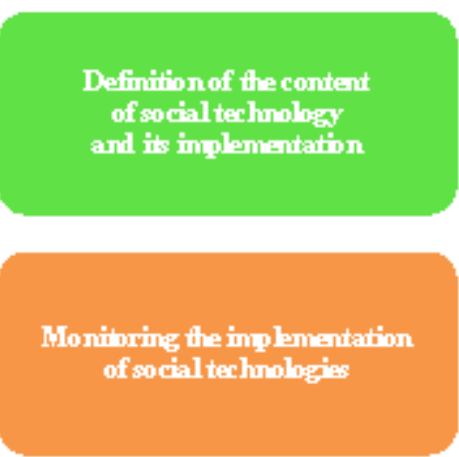

\section{- BLOOK B}

- Recuilment and Adaptation

- Staff devebpment

- The inoentives and motivation of staff

- Foming a serse of job satiffaction

- Foming a cohesive team

Fig. 3. Author's algorithm of realization of social technologies in the sphere of personnel management

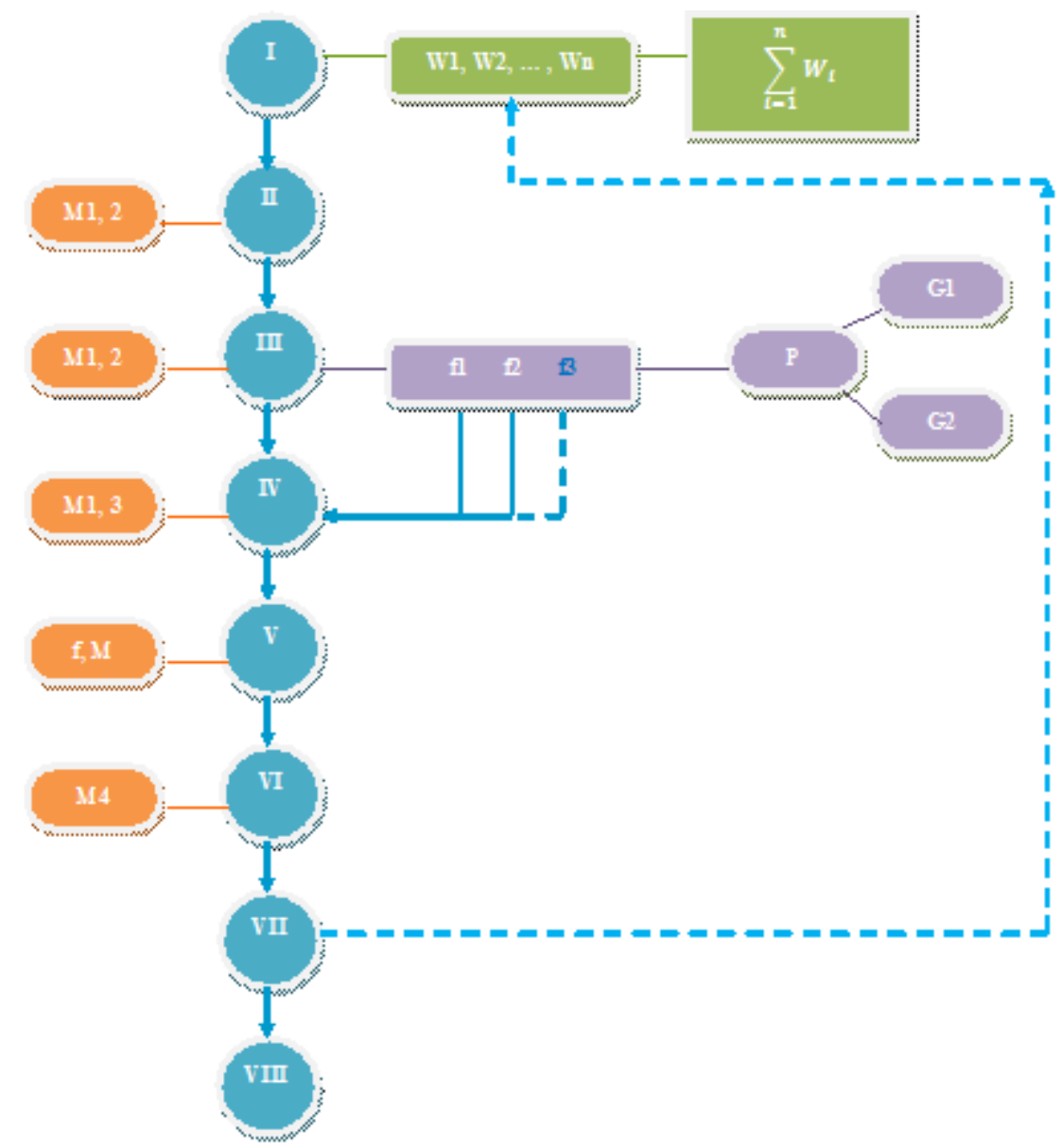

Fig. 4. Schematic reflection of social technologies "staff development" 
explored the characteristics of the happened changes over the last 5 years in the social situation of the regions of the Ural Federal district. The author found that only $12,8 \%$ of the population of the Urals Federal district and $7,7 \%$ of the inhabitants of the Tyumen region assess the changes in social status as negative (Shcherbakov, 2008). Based on these data, we can conclude that at the enterprise level, the happened changes have had a much more negative effect.

\section{The ratio of staff to monitoring by supervisors}

However, more respondents negatively assessed the changes that have taken place in terms of the control of the immediate superiors and higher heads. So, according to the statements of individual respondents "the degree of bureaucratization has increased, and every action requires approval”, "working time is spent inefficiently in conjunction with regular meetings, planning meetings, briefings, etc.”. In total

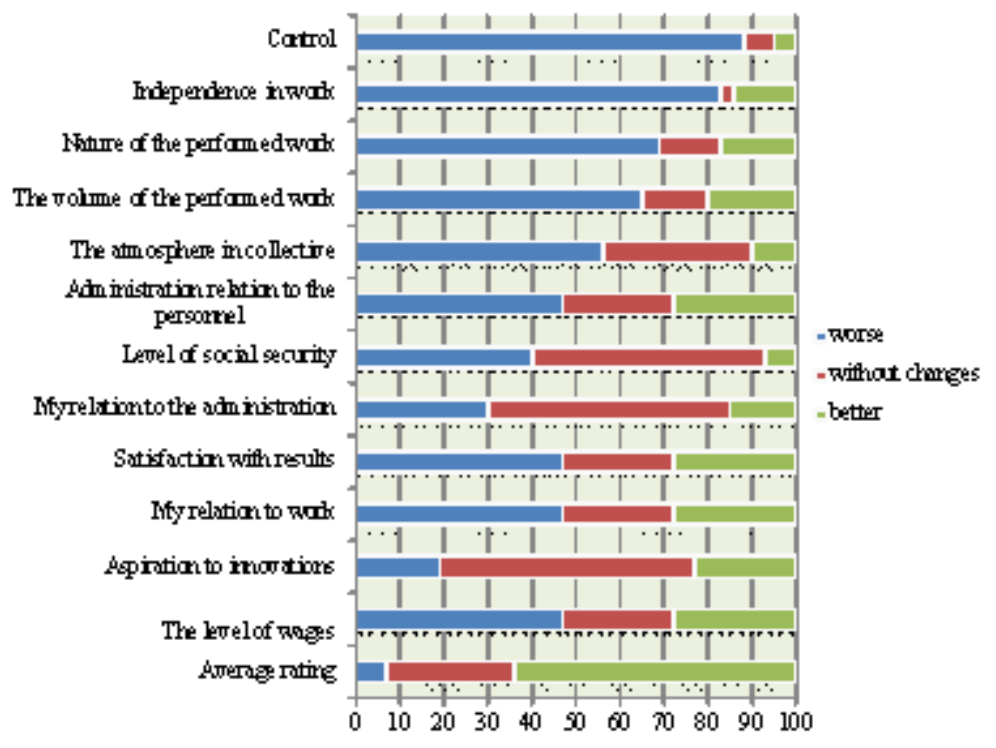

Fig. 5. Assessment the nature of the changes by respondents (in \% of respondents)

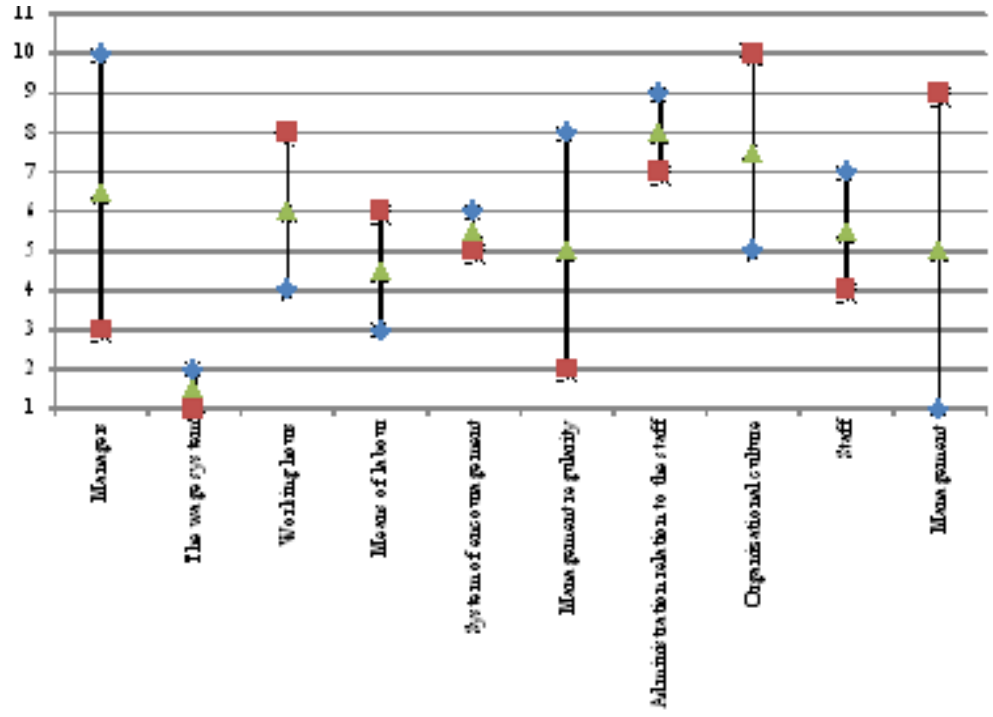

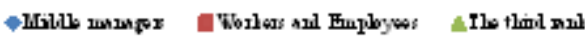

Fig. 6. The ranks of factors requiring changes 
negative changes in part of control were noted by $88 \%$ of respondents (Figure 5 ).

The authors have found a negative assessment of changes in the atmosphere in the team (56\%), the volume and nature of performed work (65 and $69 \%$, respectively), as well as the degree of autonomy in work (83\%). The latter correlates with the negative assessments of changes in control functions.

Thus it should be noted that there are much more negative assessments among them. Depending on the age it is revealed that respondents of older age express a negative evaluation more often, according to the authors, that is connected with certain conservative views and, as a result, a high resistance to changes.
The positive assessment to the changes happening in the organizations was given by only $28 \%$ of respondents. This allows us to formulate a conclusion about the ineffectiveness of the system of personnel management to the ongoing social changes. Besides, in the operating system the social mechanisms allowing to level resistance to changes which are inherent in any collective in various degree aren't established. In the studied organizations such mechanisms are not used or used very inefficiently. The authors believe that for alignment of negative perception of the happening social changes it is necessary to carry out explanatory work more carefully and to introduce social technologies.

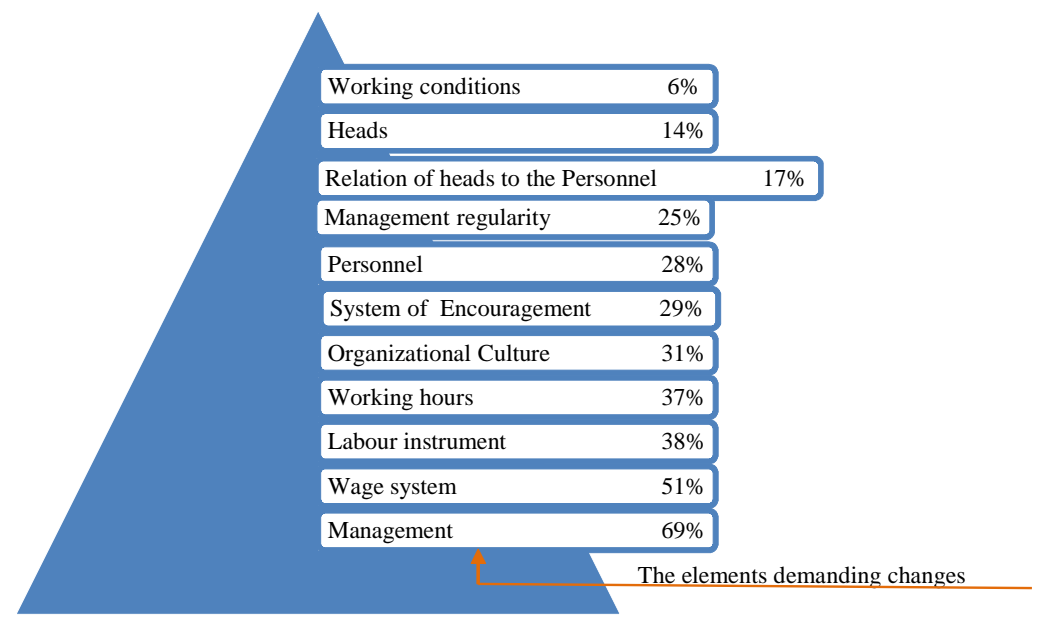

Fig. 7. The distribution of responses from the middle managers to the question about the need for change certain elements (in \% of respondents)

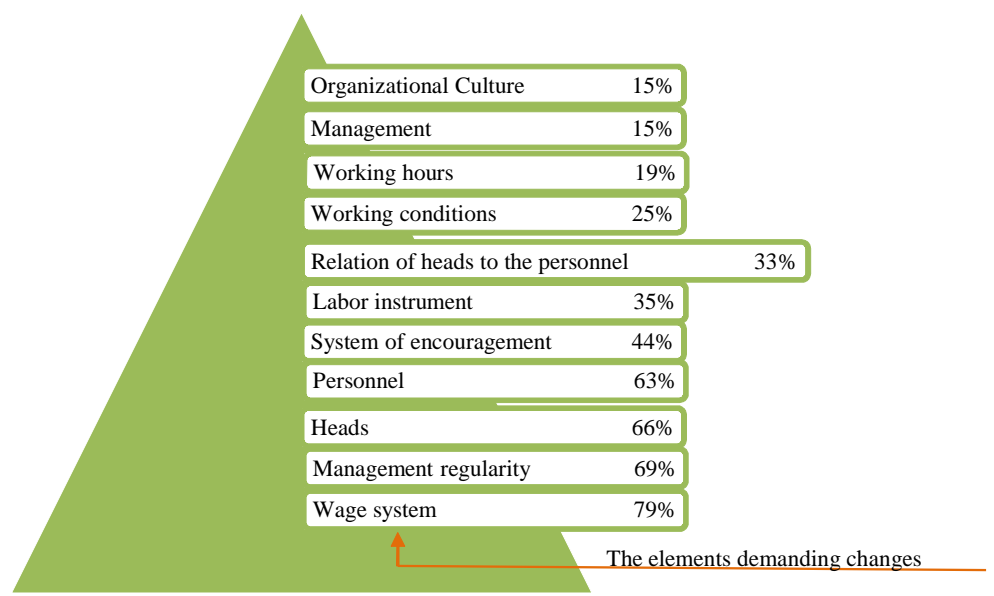

Fig. 8. Distribution of answers of respondents-workers and employees to the question issue of the need for change certain elements (in \% of respondents) 
Thus, any influence of management should be based on a compensation mechanism, which consists of the adjustment of not only those areas, which are changed under the influence of external factors, but also those in which the workers are interested. Decisions should be carried out even if the objective need for such changes at this stage is absent or the enterprise is unable to implement them (Bakhtizin, et al., 2014). To confirm this hypothesis, respondents were asked a question about what it was necessary to change in the organization from their point view. The question was open, the generalized contents of answers is given below.

1. Leaders. The subjective opinion of respondents testifying to necessity to replace management personnel at various levels due to professional incompetence or discrepancy for the post are generalized in this group of answers. This group didn't include the answers indicating the need for replacements of the head because of his personal qualities.

2. The wage system. This group of answers unites the size of a salary and an order of its definition, the size and frequency of material remunerations, justice of distribution of remunerations, etc.

3. The mode of operation. Most of the answers in this group are related to the need to review the current practice of overtime, work and also (in some cases) with the introduction of flexible working hours.

4. Means of labour. Instructions on need of updating of material base of the enterprises appear in this group of answers.

5. A system of rewards, as a group, includes the procedures and instruments of rewards except for material remunerations.

6. The regularity of management: development and implementation of adaptation programs, assessment, rotation of personnel, development of internal regulations, distribution of powers and duties, responsibility, description of business processes, etc.

7. Relation of heads to the personnel. The group compiled the answers of respondents who do not question the professionalism of managers, but consider their management style unacceptable.

8. Organizational culture: the nature of communication in the organization and outside of it, the ethics of relationships between workers.

9. Personnel. Some respondents noted that they are "forced to work with Amateurs", indicating the low level of preparedness, which entails a large number of errors or slows down of the production process, actually imposing additional duties on other employees. In particular, the statements of the following character were met: "If you dismiss the Surname N.M., it will only be better - you'll remade everything, and he will receive the salary. Give his job to me but I demand for adequate wages".

10. Management. This group of responses includes an assessment of actual management practice and points to the weaknesses such as the lack of a unified development strategy, poor planning, failure to consider the relationship of the staff to ongoing or planned changes. The received answers were ranked in decreasing order of quantity of mentions by respondents from the group "Workers and Employees" and "Middle managers". In Figure 6 the schedule of distribution of ranks of the factors demanding changes is submitted.

The idea of revision of system of compensation has found the greatest support among men till 35 years old whereas most women, regardless of age, has supported the change of an operating mode and updating of means of labour.

Heterogeneity of estimates highlighted by the respondents of different groups attracts attention. Particularly we highlight strong differences in the assessments of the need for change management (the least amount of assessments of middle managers and the third rank among workers and employees), management and the regularity management. The most unanimity is noted in terms of the need for change of the wage system, reward system and management relations to the personnel.

By average estimates of respondents, wage system demands priority changes, so as means of labour, management and its regularity demands changes. The last step is to change the 
attitude of the leadership to the staff and organizational culture.

Figure 7 shows data on the percentage of the respondents of middle managers who reported the need to change the corresponding element.

Figure 8 provides information on the shave of respondents-workers and employees who reported the need to change the corresponding element.

\section{DISCUSSION}

The results of author's research allowed to reveal that every third doesn't consider necessary to change anything. Among them older age groups predominate who hold conservative views or who are really satisfied with working conditions. This state of affairs can be considered in two ways: on the one hand it demonstrates the inertness of a certain stratum of the team, on the other hand, it has an empirical basis consisting in the existing experience. Such statements of respondents like "nothing will help", "tired doesn't help", etc. testify to favor of the latter conclusion. The sociological research conducted by us showed that there are problems in the sphere of wages in the enterprises. As it was established by the Fund "Public opinion", the amount of remuneration is one of the main motives of labour activity. Thus, "for most of survey respondents when choosing a job, the determining condition is the level of wages (34\%). On the second place (5\%) the respondents put the interest in the work and moral satisfaction that it brings... ".

According to the results of the conducted survey in the observable organizations violation of the principle of social justice and existence of a problem of motivation of the personnel, caused by insufficiently high level of a salary is revealed.) This problem is compounded by the fact that many respondents are not satisfied with the increase in wages and hope for a regular review of its value.

\section{CONCLUSION}

The requirements dictated by the entry into a new period of civilized development, lead to the transformation of the system of personnel management, accompanied by processes of changing norms and the transformation of ideas about their adequate building (Farkhutdinov and Bondarenko, 2014). The system of personnel management, earlier in the conditions of stable development, corresponding to environment parameters rather well, it comes into conflict within it in modern conditions. Inconsióstency of a converting vector to personnel strategy of the organizations leads to deterioration of indicators of their activity. Insufficient definiteness of the concept of social space and nature of proceeding social changes do problematic course of adaptation processes in the sphere of personnel management of the enterprise. At the same time, the conducted research showed that the considerable part of the Russian enterprises and their heads aren't ready to reduction of personnel management systems to the conditions dictated by the proceeding social changes. It leads to the necessity of formation of the mechanism of transformation of the personnel management system, the study of adaptive management as a factor contributing to the adaption to social changes and introduction of social technologies as a transformative instrument of personnel management system. That is what determines the relevance of the research of interaction of processes of social changes with the changes of management paradigm and its influence on a personnel management system of companies.

\section{REFERENCES}

1. Bakhtizin, R.N., Bondarenko, A.V., Lukijanov, M.Yu., The Important of Russia's Oil and Gas Policy for Global Economy. Eurasian law journal, 2014; 11: 8-11.

2. Bakhtizin, R.N., Shammazov, A.M., Rodionov, L.N., Ordered to survive, or the State University Methods of adaptation to a market economy. University Management, 2001; 3(18). Retrieved from http://ecsocman.hse.ru/univman/msg/ 145274.html

3. Bondarenko, A.V., Review roundtable at Moscow State University Lomonosov "WTO rules in the rule of law in Russia and the Customs Union. Eurasian Law Journal, 2014; 1: 183-185.

4. Bondarenko, A.V., A strong Russia - the key to regional stability and security. Eurasian Law Journal, 2014; 7: 8-10.

5. Belonozhko, M.L., Lavrischev, M.P., Priority professional competence of managers in terms of globalization: search and optimal model. Basic 
Research, 2013; 10(6): 1375-1380.

6. Belonozhko, M.L., Skifskaya, A.L., Organizational basis for the functioning of government at the regional level. News from higher educational institutions: Sociology, Economics, Politics. Tyumen, Russia: Tyumen State Oil and Gas University, 2011; 184.

7. Farkhutdinov, I.Z., Bondarenko, A.V., International law on the threshold of change: a view from the Moscow State University. Eurasian Law Journal, 2014; 1: 11-14.

8. Gaisina, L.M., The modern social recruitment technology in the Russian oil and gas companies. Bulletin of Bashkir University, 2010; 4: 12641268.

9. Gaisina, L.M., Social technologies as a tool to transform the HR management system. Power, 2015; 4: 155-160.

10. Gaifullin, A.J., Sadykov, R.M., The position of today's youth as a factor of social security: a regional perspective. Saarbruecken, Saarland University, 2012.

11. Gaifullin, A.Y., Rybalko, N.V., The dynamics of the political activity of youth. The messenger VEGU, 2011; 6: 20-22.

12. Indicators of living standards of the Russian Federation. Income and expenses. (2015, June 9). In Russian Federal State Statistics Service. Retrieved June 9, 2015, from http://www.gks.ru/ wps/wcm/connect/rosstat_main/rosstat/ru/ statistics/wages/
13. Ivanov, V.N., Patrushev, V.I., The innovative social technologies state and municipal government. Moscow, M: Economy, 2001.

14. Korel, L.V., Sociology adaptations: Etudes apology. Novosibirsk, SB RAS, 1997.

15. Khairullina, N.G., Human Resource Management in trade companies. Tyumen: Tyumen State Oil and Gas University, 2012.

16. Magura, M.I., Management of motivation. Personnel Management, 2004; 17: 34-40.

17. Mikhaylovskaya, I.M., Sultanova, E.A., How to motivate programmer. Proceedings of the international scientific-practical conference: Information Technology. Problems and solutions. Ufa, Russia: Eastern Printing, 2014; 144-146.

18. Silin, A.N., \& Khairullina, N.G., Human Resource Management. Tyumen: Tyumen State Oil and Gas University, 2004.

19. Stefanov, N., Social Sciences and the use of technology. Moscow, M: Thought, 1976.

20. Shcherbakov, G.A., Problems of formation and development of social policy in the regions of the Ural Federal District: the sociological approach. Management in social sphere, 2008; 10: 47-54.

21. Toshchenko, Z.T., Sociology. General course. Moscow, M: Prometheus, 2001.

22. Zaslavskaya, T.I., Modern Russian society: social transformation mechanism. Moscow, M: Business, 2004. 